\title{
Simulation of the Integrated Power Supply (IPS) Technology
}

\author{
Zhongjiu Zheng ${ }^{1,2}$ \\ ${ }^{1}$ Marine Engineering College, Dalian Maritime University, Dalian, China, 116026 \\ ${ }^{2}$ Research Institute of China CNR Corporation Limited, Beijing, China, 100078 \\ email: zhengzhongjiu@163.com
}

Keywords: integrated power supply; PWM rectifier; inverter; AC/DC converter; battery charger

\begin{abstract}
The paper presents a new type topological structure for the IPS, which materializes the integrated design of inverter, battery charger and emergency power supply (EPS). The IPS is composed of a DC-AC inverter and a bi-directional AC-DC converter. When the IPS works normally, the bi-directional AC-DC converter works as a battery charger in the rectified of three phase PWM state; when the IPS fails, the bi-directional AC-DC converter works in the three phase PWM inverter as EPS. The simulation experimental results have proved the correctness and feasibility of the topological structure and the control strategies of the main circuit.
\end{abstract}

\section{Introduction}

The integrated power supply (IPS) system comprises inverter (abbr. SIV), battery charger and EPS etc as the core components for power transformation management and operation control as well as other auxiliary equipment. The SIV is a key part of the rail vehicle as the power supply for the air compressor of the braking system, the cooling fan of the main circuit system and the electricity load such as the air-conditioner set, the electric heater and the floodlight etc on the vehicle. The battery charger recharges the car batteries with direct current (DC) and functions as the power supply together with the storage battery for the control circuit and the basic DC floodlight for all the vehicle systems. The IPS system is an indispensable part of the urban rail vehicle (URV) that realizes numerous pivotal functions of it. It guarantees the reliable operation of the main circuit system of the vehicle and has a bearing on the comfort of passengers in the vehicle. Consequently, top priorities should be attached to its design.

The paper presents a new type IPS integrating SIV, battery charger and EPS which can share the DC storage batteries and realize the uniform control and monitoring of the IPS system. The IPS of the URV comprises a DC-AC main inverter and a bi-directional AC-DC converter. There into, the DC-AC main inverter adopts the topological structure of three phase six switch main circuit which directly inverts the input DC voltage, followed by output by power frequency transformer isolation. ${ }^{[1-4]}$ After that, the stable three phase four-wire $380 \mathrm{~V}$ power supply and the single phase $220 \mathrm{~V}$ power supply are achieved. The bi-directional AC-DC converter also applies the topological structure of three phase six switch main circuit which can materialize bi-directional energy conversion. ${ }^{[5-7]}$ When the power supply system runs normally, the bi-directional AC-DC converter works in the rectified three phase PWM state as the battery charger, supplying vehicles with DC110V power and recharging the storage batteries. When the power supply fails, the bi-directional AC-DC converter is applied as the EPS and runs in the inverted three phase PWM state, converting the electric energy stored in the storage battery into the three phase AC to maintain normal operation of the air conditioners and the ventilation system so as to guarantee the personal health and safety of the passengers. The new type vehicle-mounted IPS reduces the allocation of equipment, storage batteries and testing equipment, enhances the reliability of the equipment and the standards of data sharing and system analysis, improves the working efficiency and the economical efficiency of operation management and boasts great potentials for future market development. ${ }^{[7-10]}$ 
The new type IPS is the power supply system integrating SIV, battery charger and EPS, primarily composed of the main inverter and the bi-directional AC-DC converter. The structure of the main circuit is demonstrated in Fig. 1.

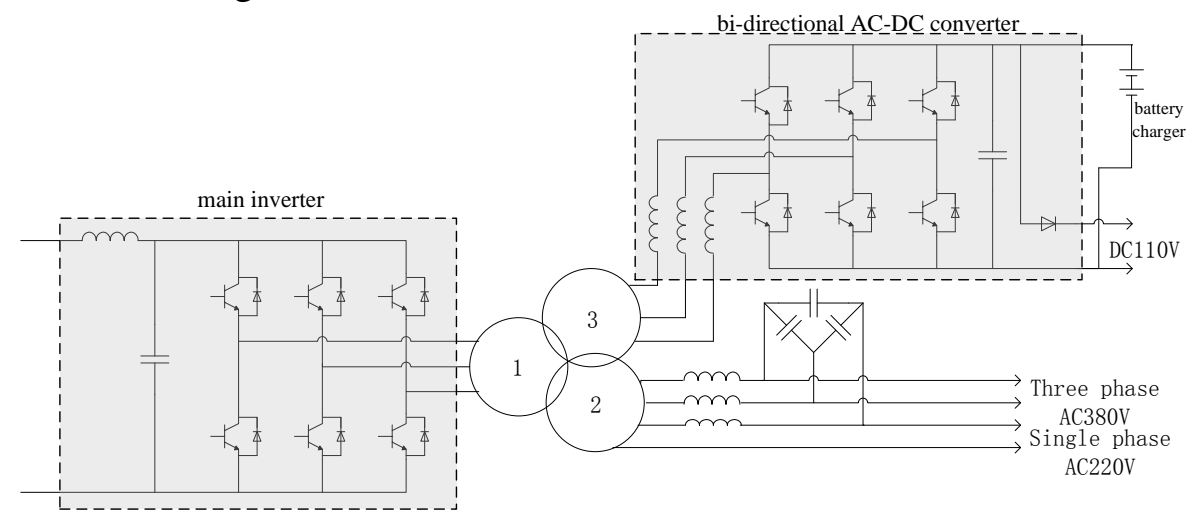

Fig. 1 Structure chart of main circuit of integrated power supply

The main inverter applies the topological structure of three phase six switch main circuit whose power device is IGBT working in the manner of SVPWM (space vector pulse width modulation). The DC input voltage is converted into the three phase PWM waves through three phase bridge inverter and becomes the sine wave converted from the smooth PWM rectangular wave voltage through three phase LC output filter so that the current at the loaded end approaches the sine curve and concurrently reduces the influence of high frequency pulse upon the inverter. In consideration of vehicle safety, electric isolation should be applied between the input voltage and the output voltage. Therefore, the $\Delta Y$ type three phase power frequency transformer is added at the output side and there is output at the neutral point to supply single phase $220 \mathrm{~V}$ power for part of the single phase load.

The isolation transformer is applied for electric isolation between line voltage and inverter output. It has three sets of coils. There into, Coil 1 and Coil 2 are utilized in voltage transformation and isolation of the main inverter, Coil 1-Coil 3 for voltage transformation and isolation during recharging and Coil 3-Coil 2 for voltage transformation and isolation during emergency inversion.

The bi-directional AC-DC converter adopts the topological structure of three phase six switch main circuit which can realize bi-directional energy conversion. When the power supply works normally, the bi-directional AC/DC converter turns the three phase PWM rectifier and applies the feed-forward decoupling double closed-loop control strategy based on the d-q coordinate system, which realizes transformation of green energy containing high power factor and low harmonic content, provides DC110V power supply for vehicles and recharges the storage batteries. When the power supply system fails, the bi-directional AC-DC converter turns three phase PWM inverter as the EPS of vehicles.

\section{Simulation Analysis of the IPS}

In order to evaluate the new type topological structure for the IPS performances, simulation has been carried out using the following parameters: input DC voltage $U_{d c_{-} i n}=750 \mathrm{~V}$, output AC phase voltage $U_{a c_{-} \text {out }}=380 \mathrm{~V}$, output DC voltage of battery charger $U_{d c_{-} b a t}=110 \mathrm{~V}$, and the switching frequency $f_{s}=5 \mathrm{KHz}$.

When the power supply system runs normally, the bi-directional AC-DC converter turns the three phase voltage PWM rectifier playing the function of recharging. The three phase PWM rectifier converts the three phase AC voltage output through the main inverter into the controllable DC voltage, with the topological structure of the main circuit.

When the power supply system goes wrong, the bi-directional AC-DC converter works in the inverted state and the electric energy stored in the storage batteries is converted into the three phase AC as the EPS of vehicles. The topological structure of the main circuit of the EPS in this operating state is indicated. 
When the bi-directional AC-DC converter works in the inverted state, the storage batteries provide DC110V control power supply and the bi-directional AC-DC converter inverts the AC power in the storage batteries into the three phase AC power, isolates the transformer and increases the voltage to three phase AC380V to maintain the normal operation of the air conditioners and the ventilation system.

The control system of the inverted power supply requires perfect dynamic and stable features. In terms of the stable features, high precision of voltage and small content of harmonic wave are required; in terms of the instantaneous features, small overshoot and rapid response are required for rapid stabilization when system load mutation occurs. Selecting the appropriate control measures exerts pivotal influence upon the features of the system. The design in the paper applies the double-loop control method based on voltage and current in the two phase synchronous rotary coordinate system, puts forth the decoupling methods targeting at the coupling relationship in the d-q coordinate and enhances the dynamic response features and tracking ability of the system with the help of the PI adjuster.

Fig.2 shows the three-phase output voltage of the main inverter which are phase separation of $2 \pi / 3$ and the phase voltage is $380 \mathrm{~V}$. The bi-directional AC-DC converter output DC voltage waveform with the PI regulator are shown in Fig.3.The DC voltage is maintained close to its reference value with a good accuracy and stability. When the power supply system goes wrong, the bi-directional AC-DC converter works in the inverted state and the electric energy stored in the storage batteries is converted into the three phase AC. Fig.4 shows the three-phase output voltage of EPS and the output AC voltage is $250 \mathrm{~V}$.

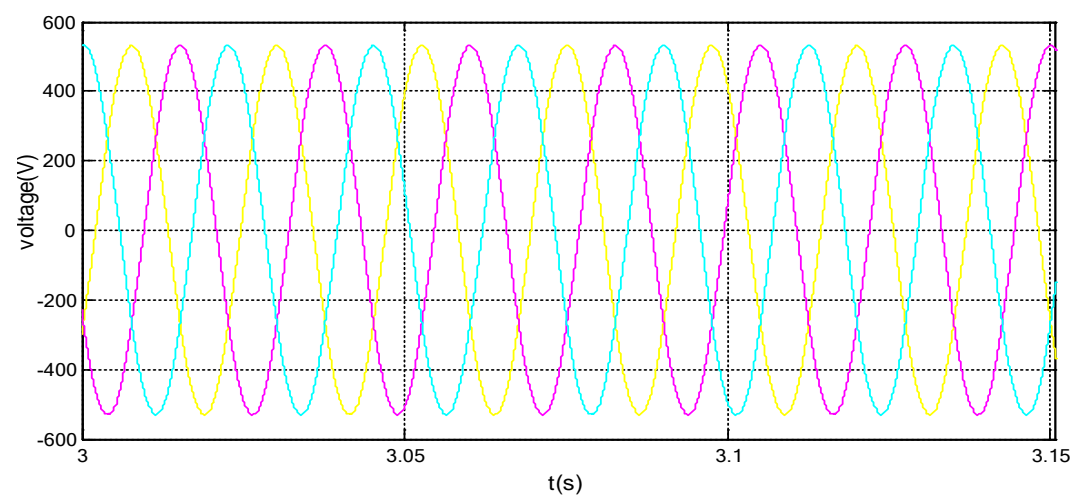

Fig. 2 Structure chart of main circuit of integrated power supply

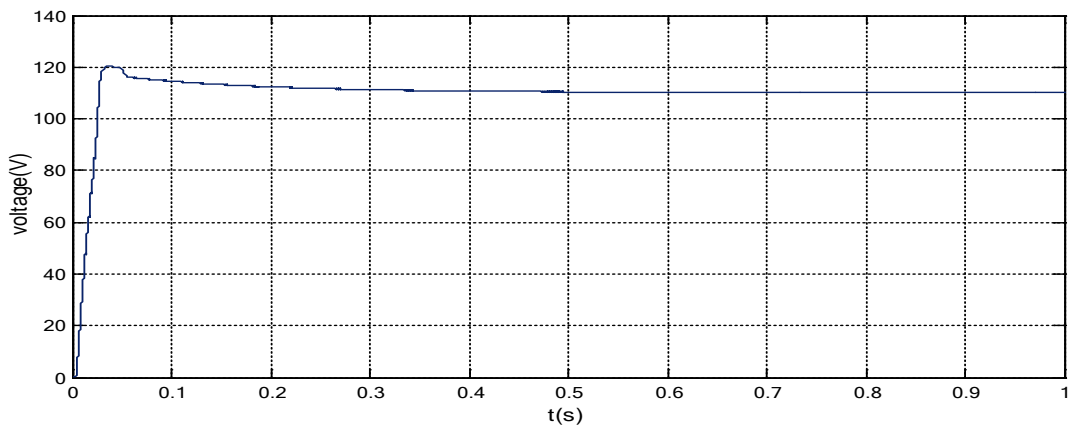

Fig. 3 Structure chart of main circuit of integrated power supply 


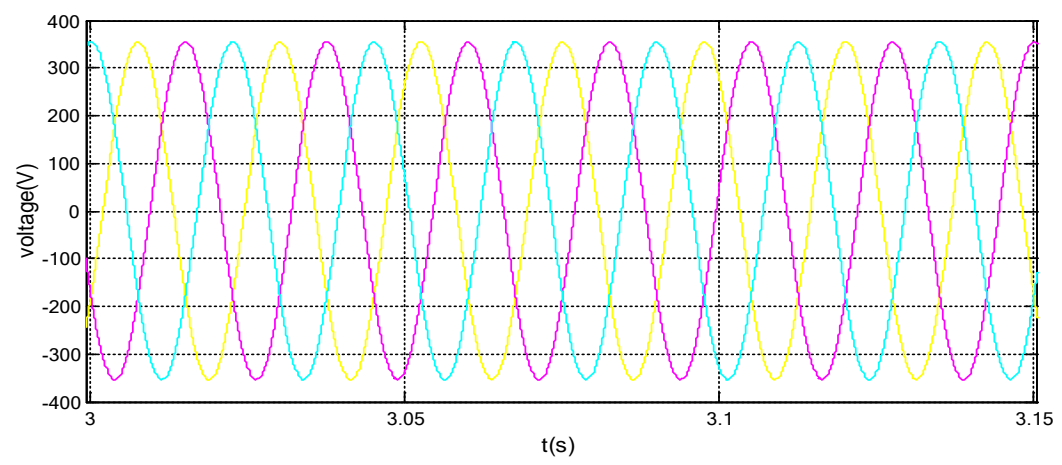

Fig. 4 Structure chart of main circuit of integrated power supply

\section{Conclusions}

This paper focuses on the new type topological structure for the IPS, which materializes the integrated design of inverter, battery charger and emergency power supply (EPS). The IPS is composed of a DC-AC inverter and a bi-directional AC-DC converter. When the IPS works normally, the bi-directional AC-DC converter works as a battery charger in the rectified of three phase PWM state; when the IPS fails, the bi-directional AC-DC converter works in the three phase PWM inverter as EPS. Simulation results confirm the improvement of the proposed new type topological structure.

\section{Acknowledgment}

This work is supported by " the Fundamental Research Funds for the Central Universities" (NO.3132014045)

\section{References}

[1] Xu Cang-su ,Yi Hong-hui,Huang Cheng-xiu,in: Experimental Study of Vehicle Modelling and Ride Comfort Simulation based on the Topology Structure Analysing, Intelligent Systems Design and Applications, 2006. ISDA '06. Sixth International Conference on, pp. 197- 201,2006.

[2] Siwakoti, Y.P. , Fang Zheng Peng, Blaabjerg, F. , Poh Chiang Loh ,in: Impedance-Source Networks for Electric Power Conversion Part I: A Topological Review, pp. 699-716, 2015.

[3] Mino, K.,Matsumoto, H.,Nemoto, Y.,Fujita, S., in: A front-end converter with high reliability and high efficiency, Energy Conversion Congress and Exposition (ECCE), 2010 IEEE,pp. 3216 3223,2010.

[4] dos Santos, E.C. , Rocha, N. , Brandao Jacobina, C, in: Suitable Single-Phase to Three-Phase AC-DC-AC Power Conversion System, Power Electronics, IEEE Transactions on,pp. 860-870,2015.

[5] Wu, J.-C. ,Sun, Y.-H.,Jou, H.-L.,Wu, K.-D., in: Three-leg power converter topology for a battery charger, Power Electronics, IET ,pp. 541 - 547,2011.

[6] dos Santos, E.C. , Rocha, N. , Brandao Jacobina, C, in: Suitable Single-Phase to Three-Phase AC-DC-AC Power Conversion System, Power Electronics, IEEE Transactions on,pp. 860-870,2015.

[7] Patil, D. , Sinha, M. ; Agarwal, V., in: A cuk converter based bridgeless topology for high power factor fast battery charger for Electric Vechicle application, Transportation Electrification Conference and Expo (ITEC), 2012 IEEE,pp. 1 - 6,2012. 
[8] Woo-Seok Choi , Jin-Wook Park, Sung-Jun Park, Chun-Feng Jin, in: A new topology of flyback converter with active clamp snubber for battery application, Industrial Technology (ICIT), 2014 IEEE International Conference on,pp. 951 - 956,2014.

[9] Xu Deng , Mecrow, B. ; Gadoue, S., in: A novel converter topology for 6 phase switched reluctance motor drives, Industrial Electronics Society, IECON 2013 - 39th Annual Conference of the IEEE,pp. 268 - 273,2013.

[10] Jia, Liang , Fang, David ; Liu, Yan-Fei, in: Control scheme for decoupling auxiliary power supply in dimmable LED drivers, Energy Conversion Congress and Exposition (ECCE), 2014 IEEE,pp. 5257 - 5264,2014. 